\title{
ARTículo
}

\section{Historias de Políticas Culturales en el Perú: un estudio de aproximación}

\author{
Histories of Cultural Policies in Peru: An Approach Study \\ Manuel Pablo Marcos Percca \\ Universidad Nacional Mayor de San Marcos \\ manuel.marcos50@hotmail.com
}

\section{RESUMEN}

En esta investigación buscamos revisar las principales obras de historia de las políticas culturales en el Perú escritas entre las décadas de 1970 y 2000 . El objetivo no es una revisión pormenorizada que culmine en una simple lista bibliográfica, todo lo contrario, buscamos vincular los aportes, tanto debilidades y fortalezas de algunas investigaciones sobre esta temática, para generar una síntesis de herramientas teórico metodológicas útiles para nuevos trabajos. Esta revisión toma en cuenta cómo se pasó de interpretaciones politizadas de las políticas culturales en el Perú (propia de la década de 1970) al análisis empírico, sistemático y crítico.

Palabras clave: Estudios históricos; Política cultural; Sector de la cultura; Plan de acciones en cultura; Décadas de 1970-2000.

\section{ABSTRACT}

In this research we seek to review the main works of history of cultural policies in Peru written between the decades of 1970 and 2000. The objective is not a detailed review that culminates in a simple bibliographic list, on the contrary, we seek to link the contributions, so much weaknesses and strengths, of some investi-gations on the subject to generate a synthesis of theoretical methodological tools useful for new works. This review takes into account the shift from politicized interpretations of cultural policies in Peru (typical of the 1970s) to empirical, systematic and critical analysis.

Key words: Historical studies; Cultural policy; Culture sector; Action plan in culture; Decades of 1970-2000. 


\section{Introducción}

[...] dado que la política cultural del Estado no ha sido explícita, hay quienes creen que el Perú no la tiene. Esto, aparte de ser conceptualmente inexacto, demuestra que quienes lo sostienen no se han preocupado de ver los esfuerzos de los diversos gobernantes por definir las líneas de política de sus programas de gobierno. Todos tuvieron lineamientos muy definidos de política cultural y algunos los hicieron explícitos en forma de leyes y decretos; sin embargo, la búsqueda de una forma de institucionalizar esta preocupación es reciente; casi tanto como lo que tiene que ver con la formalización de las instituciones estatales del ámbito social (Lumbreras, 200, pp. 81-82).

[Hoy] no tenemos un Estado que garantice los derechos culturales surgidos de las constituciones y los haga efectivos; son débiles e incapaces de trabajar para abolir las diferencias sociales (Mejía, 2004, s/n/p).

Hasta la década de 1960, en América Latina el «área cultural» aparece como un «espacio no estructurado», una «zona de la vida social» que no despierta el interés de los estados ni de las instituciones políticas. Un «área» en manos de diferentes mecenas o librada a las iniciativas de instituciones «desconectadas» y que a lo sumo fue merecedora de ensayos intuitivos o especulaciones filosóficas (García, 1987, pp. 14-15). En nuestro medio esta área comenzó a sufrir una mutación al concretarse la demanda ciudadana y de la comunidad internacional de «construir institucionalmente el área cultural» o al conformarse una organización burocrática (jerárquica, sujeta a normas, con una división reglada de trabajo basado en la especialización) capaz de racionalizar el sector, irrumpiendo así el germen de la «fórmula política cultural» (p. 15), un tipo de acción o intervención pública sobre el área cultural a fin de orientar su desarrollo.

Actualmente no existen estudios históricos dedicados a la creación y organización del sector cultura - compuesto por museos, bibliotecas, instituciones de patrimonio, formación artística, investigación, etc.- - solo se ubican exiguos trabajos sobre el Estado vistos a partir de su papel en el «ámbito» cultura o de las políticas culturales en relación a momentos político sociales. Aquí se denominará, a dichos trabajos, historias sobre políticas culturales en el Perú por el simple hecho que fueron realizados desde criterios cronológicos y el análisis e interpretación de fuentes estuvo mediado por complejas teorías sociales, políticas, económicas y culturales.

Puede afirmarse que estas obras atravesaron una suerte de «evolución metodológica». Para nuestro caso, figurarían como antecedentes de dichas narraciones sistemáticas los textos efectuados por intelectuales que trabajaron para el Gobierno Revolucionario de las Fuerzas Armadas durante la década de 1970. Arrastran, además de la ideología y una condición burocrática, el problema de la dificultad de construir y delimitar su objeto de estudio (las políticas culturales, sus órganos de gestión y actores implicados tanto en el diseño como la implementación de políticas culturales), así como de establecer un método y teoría adecuada de investigación. Por esta razón, se alude a que son producto de la especulación.

En la década siguiente, las historias de las políticas culturales son hechas desde fuera del aparato estatal y se componen metodológicamente, gracias a la capacitación de los autores en congresos y eventos internacionales organizados por centros especializados o instituciones como la Organización de las Naciones Unidas para la Educación, la Ciencia y la Cultura (UNESCO), en donde se difundieron los avances en materia de investigación y gestión cultural.

Así, las historias de políticas culturales en el país, de ser especulativas e ideologizadas, pasaron a ser investigaciones empíricas y sistemáticas; pasaron de documentar acciones politizadas a explicar, críticamente, acciones institucionalizadas. 
Llegado a este punto es preciso formular las siguientes interrogantes: ¿Por qué de pronto irrumpen historias sobre políticas culturales en el Perú? y ¿qué situaciones o circunstancias prácticas motivaron su escritura? A modo de ensayo de respuesta diremos que un detonante pudo ser la institucionalización de la acción pública en materia de cultura; es decir, la creación, por parte del Estado, de un órgano con autonomía destinado a la administración y gestión exclusiva del campo cultural en el país tras imponerse en el imaginario de la sociedad civil y miembros del Estado un modelo económico cultural internacional que aseguraba que la cultura podía generar «desarrollo». Es decir, contribuir a la democratización e igualdad material entre las naciones libres de occidente (Alcalde, 1998, 1999; Cornejo, 1979).

Asumir tal idea implicó que el Estado peruano suscribiera acuerdos de apoyo y cooperación con influyentes organismos de la comunidad internacional (como la UNESCO, con sede en París). Tras esto, dichas instancias supranacionales «recomendaron» a sus miembros «en desventaja», implementar políticas reformistas en materia de cultura y desarrollo, y con ellos reformar toda la administración de la cultura.

En aquel contexto, un régimen de turno, por ejemplo, como del General Juan Velasco Alvarado (1968-1975), se vio en la encrucijada no solo de formular, sino también implementar estas «recomendaciones», crear un órgano especial de la cultura - el Instituto Nacional de Cultura (INC) - ; racionalizar las instituciones que tradicionalmente se habían encargado de la «cultura» desde la Independencia. Había, entonces, que centralizar, organizar y efectuar la administración y gestión de la cultura en el marco de un nuevo contexto y nuevos objetivos internacionales y culturales. Incluso nuevos paradigmas (los economicistas).

Así es como el Estado convocó a científicos sociales e intelectuales, de línea progresista, en calidad de asesores de cultura. Incluso, se los incorporó como Directores Generales dentro de la nueva estructura cultural. Ellos debían acudir periódicamente a congresos internacionales de Cultura y Gestión convocados por la UNESCO y el Convenio Andrés Bello (Arróspide, 1975, p. 208). Había que presentarse y exponer «nuestra» manera de administrar el sector cultura ante una plataforma mundial. Tenían que presentar, históricamente, cómo fueron las políticas culturales en el Perú y por qué la actual era diferente. Y si era necesario, había que comisionar a los funcionarios la elaboración de monografías u opúsculos que aborden este fenómeno de racionalización de lo cultural (Ver Ministerio de Cultura del Perú, Archivo Central: INC. “Resoluciones Directorales Nros. 2601-2700, 1973". Vol. 56. Resolución Directoral N 002634, Lima, 26 de noviembre de 1973 y "Resoluciones Directorales Nros. 3201-3400, 1977”. Vol. 145. Resolución Directoral № 003250, Lima, 23 de noviembre de 1977).

Los requerimientos internacionales obligaron a los órganos culturales del Estado a decretar que su burocracia elabore semblanzas sobre las políticas culturales en el país, en una década (los setenta) donde, el Estado, las políticas públicas, la cultura y el desarrollo, no eran los temas que atraían el interés de la «nueva historia», cuyos miembros se concentraban más en la historia económica y social de «los de abajo» y no en explicar cómo los gobiernos construyeron y elaboraron sus decisiones. Así fue como se inició el diseño de narraciones sobre las políticas culturales y no fueron los historiadores quienes las hicieron.

Para culminar esta parte, expresaremos que sí es dable una revisión de investigaciones históricas sobre políticas culturales en el Perú, pues existen afinidades metodológicas entre varios de estos textos y también una evolución y abandono de visiones y modelos de análisis e interpretación histórica. A ello, se suma el hecho de que en todas estas publicaciones se concibe la política cultural como un problema y una posibilidad de mejora socio-cultural y económica 
para el país y sus autores no dudan en brindar sus propuestas para contribuir en alcanzar dicho objetivo.

Este estudio toma en cuenta cómo se transformó el análisis e interpretación de la historia de las políticas culturales en nuestro país. Es decir, cómo se pasó de una interpretación ideologizada y especulativa de la historia de las políticas culturales a un tipo de análisis empírico-crítico y también conceptual, centrado en la trayectoria de las mismas entidades públicas de cultura, en ciertos actores gubernamentales o, finalmente, en el «campo cultural».

\section{Década de 1970: Especulaciones politizadas}

Mientras otros ensayos de racionalización [...] de la realidad peruana en el transcurso del siglo XX [...] habían sido conducidos bajo el impulso de intereses apenas camuflados con ideas, el esfuerzo velasquista se manifestó desde el principio en el más serio y el más sistemático para promover una unidad nacional sobre la base de una sociedad civil integrada. La unión se realizaba en torno a una lucha más racional y productiva, en contra de la naturaleza, pero también en la perspectiva de una lucha social en contra de las injusticias internas de la sociedad y una lucha también en contra de los mecanismos de dependencia y de explotación exterior (Santuc, 1993, p. 97).

En la década de 1970 irrumpen las primeras aproximaciones históricas a las políticas culturales y área cultural. Revelan nacionalismo y politización. Se plasmaron en propuestas de acción cultural para el gobierno Revolucionario del General Juan Velasco Alvarado, en apologías a la política cultural de este régimen así como en descripciones oficiales del moderno organismo administrador del sector cultura: el INC. Pese a que sus énfasis estuvieron centrados en el papel que juega el Estado en la cultura o se concibieron en ausencia de un manejo teórico especializado, estas visiones históricas fueron importantes pues en su momento sirvieron de referencia para cualquier tipo de discusión sobre políticas y diseño de estructura de decisión cultural, las primeras que se llevaron a cabo en nuestro país. A continuación, los documentos y obras anunciadas.

Política Cultural del Perú es un informe elaborado por el INC - e impreso por la UNESCO en 1977- que buscó mostrar a la comunidad internacional cómo aplicó la política cultural el régimen Revolucionario y cómo se configuró el sector cultura en la estructura estatal. Política cultural del Perú reúne dos documentos: "Bases para la política cultural de la Revolución Peruana" (pp. 11-25) y "El Instituto Nacional de Cultura" (pp. 26-71), una descripción de las instituciones que compusieron este órgano creado por Decreto Ley $\mathrm{N}^{\circ} 18799$ del 9 de marzo de 1971 (Coloma, 2001a, p. 7).

"Bases para la política cultural de la Revolución Peruana" fue realizada en 1975 por el Concejo General de Cultura (CGC), entonces el principal órgano consultivo del INC, presidido por el Director General e integrado por un representante de los siguientes organismos: Concejo Superior de Educación; Universidad Peruana; Dirección General de Extensión Educativa; Dirección de Asuntos Culturales del Ministerio de Relaciones Exteriores y SINAMOS, más tres personas destacadas en el campo de la cultura, nombrados por Resolución Ministerial a propuesta del Director General del INC (Ansión, 1986, p. 65).

Es el primer documento en nuestra historia que contiene, explícitamente, propuestas de acción cultural para el Estado. Estas propuestas, por un lado, se inspiraron en las consideraciones de la Conferencia Intergubernamental sobre Políticas Culturales (Venecia, 1970), que indicaron que la cultura es una herramienta para el desarrollo humano y que no puede ser vista como algo marginal, que se deja en manos de élites minoritarias o grupo de poder comercial, y que los 
estados tienen que generar políticas culturales que contribuyan no solo al desarrollo económico, sino también al desarrollo humano (Mejía, 2004; Cornejo, 1989, p. 299).

Y, por otro lado, tal planteamiento se funda en teorías humanistas, anticoloniales y contradependentistas que respondían a proyectos de construir nuevas sociedades en medio de condicionamientos históricos de dominación, subdesarrollo y desigualdad. Sin embargo, mencionar solo las consideraciones y teorías en las que se cimentó "Bases para la Política Cultural de la Revolución Peruana", sería insustancial si obviamos el diagnóstico histórico que atraviesa todo este importante documento de propuesta cultural para el Estado.

Este diagnóstico es bastante parcializado y puede considerarse el principal antecedente de las historias de políticas culturales en el Perú, pues sus autores intentan el análisis de la «realidad cultural» de la nación peruana estableciendo temporalidades: etapa donde la nación peruana estuvo regida por antiguas políticas culturales (cifradas en valores coloniales e impuestas por agentes externos o gobiernos conservadores y tradicionalistas) y etapa en la que se impone una nueva política cultural: la revolucionaria (etapa actual) (CGC, 1977, p. 15).

Pero este planteamiento cronológico levantaba una barrera que impedía plantear la historicidad de las políticas culturales al desmerecer, éticamente, todas las políticas culturales no revolucionarias, no nacionalistas. Para los autores de este diagnóstico, la política cultural estatal del presidente Juan Velasco Alvarado no tenía antecedentes. Era fundacional. Obviaba vínculos con la acción cultural estatal del pasado.

Es oportuno especificar que en el diagnóstico histórico del plan estatal de cultura se menciona que la cultura peruana atravesó por un largo proceso de colonización, control y dependencia y que el régimen Revolucionario de las Fuerzas Armadas en su deseo de beneficiar a las mayorías (alienadas y colonizadas) inició una política de descolonización cultural, de revalorización de la cultura popular, de desarrollo de la conciencia crítica del pueblo, de promoción y rescate de los valores nacionales, acudiendo a medios escritos, orales, audiovisuales de comunicación social, y cuenta con el apoyo de intelectuales y trabajadores del arte.

Un punto notorio de esta visión histórica es que presenta carencias formales expresados en la tendencia a uniformizar la diversidad de experiencias e historias de actores y culturas que conforman el territorio peruano. Este ideario se esmera en concebir el Perú como una «unidad cultural» que atravesó el drama de la dependencia colonial, subdesarrollo y desintegración debido al capitalismo; y el Gobierno, sus intelectuales o sus gestores de cultura son interpretados como los llamados a diseñar una política cultural descolonizadora e integradora (desde bases populares) así como de implementarlas para su éxito.

En cierto sentido, este ideario estatal y su interpretación histórica de la cultura aparecen como la expresión del proyecto del régimen de Velasco de transformar (alterar) el ordenamiento social desde una ideología nacionalista popular. Esta visión intelectual obvió — por estrategiala diferencia y se apartó de la mirada histórica como resultado de la investigación empírica por dedicarse a crear una imagen nacional o concretar la utopía integracionista. Realmente, plasmó las visiones de intelectuales que creían, realmente, que el Estado era el aparato adecuado para la ansiada «redistribución de bienes y servicios culturales» y la transformación social nacionalista (Bueno, 1974, pp. 14-17; Ortega, 1975, pp. 18-19; Bustamante, 1975, pp. 4-5; Hildebrandt, 1976, p. 21). Quizá, simplemente, "Bases para la política cultural de la Revolución Peruana" contenía la versión histórica de un régimen que hizo «crítica» ideologizada de la cultura, que creía que la 
posibilidad de revolución cultural no podía venir de las estructuras sino de la acción coordinada con ciertos individuos dotados: los intelectuales (escritores, artistas, científicos sociales, etc.).

Otra publicación germinal de historia de las políticas culturales en el Perú es esa suerte de apología de la política cultural del régimen nacionalista-revolucionario del General Velasco Alvarado escrita por uno de sus funcionarios e ideólogos. Es la reflexión de un protagonista, de un miembro del Concejo General de Cultura, Cesar Arróspide de la Flor (Lima, 3 de enero de 1900 - Lima, 4 de julio de 1992) y que optó por titularla, Cultura y Liberación (1975). Un rasgo fundamental de la obra de este crítico de arte, maestro y musicólogo, es que sitúa el «problema» de la política cultural en un escenario social, nacional e internacional (aunque de dependencia) e incorpora elementos artísticos «populares» o nacionales en dicho escenario. Estas apologías de intelectuales de gobiernos tuvieron el mérito de documentar y buscar una lógica a las acciones desarrolladas por el Estado (García, 1987, p. 19) pese a no ser el resultado de un estudio histórico empírico ni sistemático, sino de una interpretación recubierta de utopías y encubrimiento de la diversidad cultural.

En Cultura y Liberación, Arróspide maneja categorías que le permiten sustentar su visión de las políticas culturales desde una perspectiva nacionalista como, por ejemplo: «realidad nacional», «integración nacional», «mestizaje». Maneja una visión de la historia cultural conciliadora e integracionista por ideología — como los historiadores tradicionales. Para este intelectual existiría una «realidad cultural nacional» que atravesó por un proceso histórico de dominación, dependencia y dispersión cultural. En su enfoque no tiene cabida la problemática marxista de la «lucha de clases» ni la liberal culturalista de «diversidades sociales y culturales» que conviven en un territorio y que presionan, pugnan y concilian con el poder en pos de participar de la cosa pública.

Este autor casi no habla de las diversidades que conforman el territorio, mucho menos - y esta vez en clave marxista - de «síntesis de contrarios». Arróspide hace referencia de la identidad cultural nacional. Asume la unidad de la diversidad cultural por artificio. Su visión de la cultura, de la dominación cultural de la nación y de la política cultural revolucionaria, no es el resultado de un estudio empírico sobre acciones gubernamentales específicas o sobre la experiencia histórico cultural de los diversos grupos o «clases» sino del deseo de dar una respuesta a la premisa ideológica: existe la dominación cultural de la «nación peruana». Y su visión histórica es una historia de este supuesto en el cual, al final, una política cultural de un régimen reformista militar y centralista impondrá la solución con libertad.

Otro elemento destacado de la obra en mención es que en ella habita una ausencia, y es el sujeto social. En términos actuales, en Cultura y liberación no se vislumbran los actores sociales que participan del área cultural. Lo que hay son políticas liberadoras diseñadas por el único actor visible: el intelectual que forja y aplica la política de liberación cultural en clave nacionalista (por momentos indigenistas y antropológicos).

Hasta aquí, inspirados en Néstor García Canclini, esta breve revisión crítica de la metodología y estructura conceptual del libro de Arróspide, quien durante el gobierno de Bustamante y Rivero (1945-1948), tuvo una breve gestión como encargado de la Dirección de Educación Artística y Extensión Cultural del Ministerio de Educación Pública, primer ente creado, en 1941, por el Estado (mediante la Ley Orgánica de Educación Pública $\mathrm{N}^{\circ}$ 9359) para que se encargue exclusivamente de lo que ahora se denomina «sector cultural» y «promoción cultural», hecho que podría marcar nuestro ingreso a la «modernidad» en materia de política y gestión cultural (Cornejo, 1987, pp. 7, 51-52). Cabe precisar que fue el literato, profesor, y activo difusor cultural, Manuel Beltroy, quien funda y dirige esta dirección hasta 1943 (La Prensa, 1955, p. 10). 
Es necesario especificar que esta minúscula Dirección de Educación Artística y Extensión Cultural del Ministerio de Educación Pública de inicios de la década de 1940 — dependiente del sector Educación - trató y entendió la cultura como Bellas Artes, como una realidad o campo autónomo cuyas manifestaciones debían promocionarse en los centros de educación mediante diferentes medios. La participación de Arróspide en el INC, creado por Velasco en la década de 1970, nos revela no solo que para esos días funcionaba un gran órgano público burocratizado encargado de elaborar y efectuar la política cultural del Estado en las áreas de promoción y difusión cultural, conservación del patrimonio monumental y cultural y formación artística sino también nos revela la primacía de una nueva visión sobre la cultura por parte del Estado: una herramienta para concretar utopías de transformación de todo el orden social o desestructuración de la «marginación cultural». Atrás había quedado la etapa en que el órgano estatal de la cultura, como la Dirección de Educación Artística y Extensión Cultural, se dedicaba solo a la difusión cultural de lo más destacado del campo de las artes cultas o artes otras, siempre en clave culta.

\section{Década de 1980: Políticas culturales explicadas como un producto de cambios socio políticos}

El texto de Juan Ansión, Anhelos y sinsabores. Dos décadas de politicas culturales del Estado Peruano (1988) [1986], evidencia el abandono de la lectura y tratamiento especulativo de la trayectoria de las políticas culturales en el Perú. Revela la irrupción de alguien que intenta estudiar el papel del Estado en la cultura en relación a situaciones sociales, políticas o a discursos. Maneja el método histórico y la teoría social. Reconoce acciones gubernamentales y actores específicos en materia de diseño, gestión e implementación de políticas culturales, como el burócrata, el escritor y el artista como, por ejemplo, José María Arguedas o Martha Hildebrandt (Ansión, 1988, p. 25). Analiza la subjetividad de estos actores, los vuelve en agentes clave de la explicación histórica.

Nos interesa analizar la lógica de los principales actores que fueron configurando la política cultural del Estado [entre 1962 y 1985. También] nos interesa descubrir cómo los cambios políticos y burocráticos van ligados a ciertas maneras de actuar que sólo en parte dependen de la voluntad y de la conciencia de los individuos (Ansión, 1988, p. 141).

Como Ansión está interesado en mejorar la gestión pública en materia de cultura, analizará las variaciones y sinsabores de las políticas culturales durante los gobiernos de Fernando Belaunde (1963-1968 y 1980-1985) y del régimen militar (1968-1980), así como el rol de los diferentes sujetos que conforman la burocracia estatal (Ansión, 1988, p. 19). Asimismo, y como prueba de seriedad académica, no vacila en exponer los límites y arbitrariedad de su obra:

En este estudio, nos hemos centrado en los hombres que "hacen políticas", sin poder analizar detenidamente los efectos de sus políticas en la sociedad. Esto supone en parte la aceptación de nuestra renuncia momentánea a abordar el tema mismo de la actividad cultural en su desarrollo. Es, pues, una visión "desde arriba", desde el poder político y el aparato estatal. La ausencia de estudios previos sobre nuestro tema, nos forzó a arrancar desde un ángulo que nos permita adentrarnos en los mecanismos de elaboración de políticas y de funcionamientos del aparato estatal, como una manera de abrir campo a futuras investigaciones que estudiarían el fenómeno cultural desde el punto de vista de la sociedad misma: el de los creadores, transmisores y receptores de la cultura (Ansión, 1988, pp. 25-26).

Anhelos y sinsabores se construye en base a entrevistas y documentos de política y de planificación burocrática (Ansión, 1988, p. 141); hace concordar el discurso con la situación histórica y política del momento; da énfasis por aclarar conceptos, como qué es cultura, política 
cultural, burocracia y cuál es su rol en el cumplimiento de los programas político-culturales, entre otros. Por eso, es la primera obra histórica estructurada sistemáticamente.

En cada pasaje de Anhelos y sinsabores (la primera edición apareció en 1986) se detecta una búsqueda por cumplir a cabalidad los objetivos base: analizar la política cultural del Estado relacionándola con trasformaciones sociales y políticas definidas. Veamos:

[Ante] el auge del movimiento campesino en la sierra [...], el populismo del [primer gobierno del arquitecto Fernando Belaunde Terry], recogiendo la antigua tradición andina del trabajo comunal, incorporó como eje central de la política de gobierno las obras realizadas por "cooperación popular", es decir por el trabajo voluntario colectivo de los beneficiarios.

La referencia al incario es explicita y, de hecho, el Estado pretendió entonces utilizar el antiguo método prehispánico, para hacer trabajar a las comunidades, en integrarlas a la sociedad nacional [...]. Esta suerte de neo indigenismo estatal, por más tibio o inconsecuente que haya sido de modo general, fue capaz de arrastrar en sus inicios a importantes sectores de la juventud universitaria y abrió un espacio que hiciera posible el trabajo de la Casa de la Cultura del Perú en esos años. Primero bajo la dirección de José María Arguedas y luego de Fernando Silva Santisteban, ambos antropólogos apasionados del mundo andino, se fue rompiendo la imagen de la cultura como patrimonio exclusivo de "élites" intelectuales y artísticas, para ponerse a la cultura indígena en el centro del debate. [...] Sin dejar de lado otros aspectos, ese periodo [19621968] se caracterizó sobre todo por el énfasis puesto en el apoyo a lo indígena (Ansión, 1988, pp. 45-46).

En esta misma línea no se puede obviar otro importante fragmento del texto:

[...] el reformismo de Belaunde, basado en la concepción arquitectónica del desarrollo (con énfasis en las obras de infraestructura), no dejaba de mantener las ambigüedades de la vieja clase dominante con respecto al indio: valorando su cultura para utilizarla mejor en beneficio de la política del Estado. El general Velasco, quien marcó con su sello personal un movimiento de indudable corte institucional, fue mucho más radical y moderno (Ansión, 1988, p. 48).

Los cambios políticos y burocráticos en los órganos de cultura, por efecto de las maneras de actuar de los individuos, reciben un trato esplendido en Anhelos y Sinsabores:

[En la década de 1960] los directores la Casa de la Cultura "pre-revolucionaria" no tenían su interés principal puesto en el desarrollo de la institución como tal, ni buscaba dirigir el proceso cultural, sino apoyarlo, impulsarlo. El "proceso revolucionario" [del régimen del General Juan Velasco Alvarado] en cambio se apoyaba en la burocracia.

Una burocracia más tecnocrática y ejecutiva, y también más dirigente, convencida de la necesidad de "concientizar" al pueblo, y segura que antes de ella nada bueno se había hecho.

El Estilo era diferente, y sobre todo quería diferenciarse. Sin embargo, se reproducían antiguas estrategias, como buscar respaldo en las altas esferas del gobierno; "pelear" el presupuesto; poner por delante la solución material antes que la formal (Ansión, 1988, p. 159).

Otro libro de la década de 1980 que evidencia el abandono del tratamiento especulativo de la historia de las políticas culturales en el país es Estado y cultura en el Perú Republicano (1987), del Director General del INC (del 18 de octubre de 1976 al 26 de diciembre de 1978) y consultor de la UNESCO, Jorge Cornejo Polar (Arequipa, 1930 - Lima, 2004). Pretende explicar los efectos sociales de las políticas culturales estatales. Lanza la hipótesis de que el pueblo, el verdadero creador de la cultura, ha permanecido en general al margen de las políticas culturales y que la 
historia de las políticas culturales en el Perú es la historia triste de una larga serie de desencuentros entre la voluntad de los gobernantes y las verdaderas necesidades de los gobernados. Las políticas culturales no enfrentaron el hecho de que el Perú es un país multicultural y plurilingüe. La diversidad cultural es uno de los problemas básicos de la nacionalidad.

El problema central es pues el desfase entre la vida cultural espontánea y el aparato legislativo y administrativo o, si se prefiere, entre el país real y el país formal [...]. La política cultural del Estado marcha por un lado y la vida cultural de la población - la de los creadores y la de los consumidores - marcha por otra, independiente, por lo general, a los afanes gubernativos (Cornejo, 1987, pp. 49-50).

Para demostrar su conjetura Cornejo analiza, sistemáticamente, cómo el Estado Peruano fue atendiendo la cultura (la «culta» y la «viva») a lo largo de la República (1821-1985) mediante la creación de diferentes organismos de gestión e implementación de políticas culturales. Su análisis cobra sistematicidad porque «acomoda» su objeto de estudio (el Estado y la cultura) al criterio (cronológico) de las etapas o periodos, que considera fueron siete (de 1821 a 1895, de 1895 a 1919, de 1919 a 1941, de 1941 a 1962, de 1962 a 1971, de 1971 a 1985).

Al respecto, indicaremos que para este autor en los primeros momentos de la República predominó la preocupación por el desarrollo de las artes cultas y la conservación del patrimonio. En etapas posteriores, emergieron nuevas preocupaciones concernientes a los diversos «componentes del desarrollo cultural»: educación escolar y extraescolar, comunicaciones de masa e industrias culturales, cultura científica, medio ambiente. Las políticas de las etapas finales «sería» la política de desarrollo en todos sus aspectos la que se ve arraigada por la preocupación cultural.

Asimismo, es importante precisar que la base sobre la que este profesor, crítico e investigador de la literatura hispanoamericana y miembro de la Academia Peruana de la Lengua Española (Bueno, 2005), inició su investigación, fue la recopilación metódica y la subsecuente crítica de constituciones, leyes, decretos, mensajes, planes de gobierno «y otros testimonios semejantes en todos los cuales han quedado plasmadas las actitudes de los sucesivos gobiernos frente a la cultura» (Cornejo, 1987, p. 2). También se preocupó en esclarecer los conceptos que utiliza: cultura, desarrollo cultural en el Perú (pp. 46-48), «democratización de la cultura»y «democracia cultural» (pp. 61, 78, 117), «derecho a la cultura» (pp. 97-100).

Son varios los pasajes destacados del libro. Respecto al problema del desfase entre la vida cultural espontánea y el aparato legislativo y administrativo o del «desencuentro entre las políticas culturales estatales y la realidad socio cultural del país» o el «desajuste» entre legislación y administración cultural de una parte y cultura viva, actuante, de otra (Cornejo, 1987, pp. 50, $63,84,127)$, el estudioso consideró que se dieron ciertas mejoras a partir de la década de 1960, cuando irrumpieron nuevos actores sociales y políticos que buscaron interpretar las inquietudes y anhelos de multitudes ansiosas de mejores niveles de vida pero desorientadas (pp. 48-49, 65). No obstante, asegura:

Digamos que, si bien en algún momento de la década de 1970 se avanzó considerablemente en el ámbito de la política cultural, en ningún momento llegó a superarse del todo el viejo problema de la desconexión entre los trabajos y las leyes provenientes del Estado y la bullente, imprevisible y dinámica vida cultural espontanea de la comunidad. Más aún, se dio la paradoja de que en el momento de que el Estado — con la creación del INC - evidencia su máximo esfuerzo en este campo y demuestra su elevado grado de conciencia respecto al rol de la cultura en el proyecto nacional, son los mismos creadores (en alguna proporción) quienes manifiestan 
dudas, escepticismo y a veces franca hostilidad frente al INC u sus acciones. Cruel paradoja sin duda que revela cuán difícil es acertar en el terreno de las políticas culturales estatales (Cornejo, 1987, p. 128).

De otro lado, para este hombre de humanidades, el periodo 1919 a 1941 también fue testigo de un considerable avance en cuanto a la actividad cultural del Estado en los ramos de respeto a la cultura andina y valoración de lo indígena; aunque aclara que la política cultural del Estado marchó por un lado, mientras que la vida cultural de la población marchó por otro, independiente por lo general de los afanes gubernativos (Cornejo, 1987, p. 49). Posteriormente, Cornejo considera que para acortar el desencuentro entre administración cultural y realidad cultural nacional debe haber respeto, esmero y compromiso de quienes diseñan e implementan políticas culturales que realmente puedan servir a la cultura viva de todos los pueblos del Perú (p. 85).

Refiriéndose al trato que - entre 1821 y 1885 - dieron los diferentes gobiernos a la cultura, Jorge Cornejo asegura que «El Estado, [...] pasada la efervescencia inicial en que emancipación es sinónimo de difusión de la educación y la cultura, cae en la ineficiencia o lo que es tal vez peor en la indiferencia» (p. 23). Y continúa:

[...] los gobernantes-representantes del Estado permanecen, en general, pasivos e indiferentes como impermeables al movimiento que busca con dispares resultados echar los cimientos de la cultura nacional peruana [por ejemplo] en la literatura. Su accionar es escaso, inorgánico, muchas veces inútil. Se limita [... ] a algunas creaciones específicamente culturales como la Biblioteca, el Museo o el Archivo, a otras más bien educativas como universidades, colegios o escuelas, a vagas declaraciones de estímulo a las artes y a las letras y poco más. Pareciera que el país oficial ignorara o diera las espaldas al país real (Cornejo, 1987, p. 24).

Agrega que tal vez el hecho más significativo para la esfera de la cultura, en el siglo XIX, es la creación del Ministerio de Instrucción Pública, Beneficencia y Asuntos Eclesiásticos el 4 de febrero de 1837, bajo el gobierno del Mariscal Andrés de Santa Cruz, Presidente de la Confederación Perú-Bolivia. En dicha fundación estaría el comienzo del proceso hacia la autonomía del Sector Educación en el mundo de la administración pública nacional. Y esta autonomía fue a su vez requisito previo a la posterior autonomía del sector Cultura que se alcanzó solo, aunque no a cabalidad a mediados del siglo XX.

La diferenciación entre los ramos cultura y educación fue clave para ingresar a una etapa de modernización. Las normas que se dictaron para administrar la educación y la cultura dejaron de ser similares. El Estado comenzó a tener una posición diferenciada en cuanto a la esfera cultural y mediante diversos casos Cornejo demuestra que fue la alta cultura el patrón con que se diseñaron las primera políticas culturales modernas (1941-1962) negándose así que había en el Perú una cultura autóctona y una popular (p. 60).

Respecto a cómo se dio el proceso de modernización del sector cultura, Jorge Cornejo explica que éste se inicia con la Dirección Artística y Extensión Cultural, creada por la Ley 9359 (Ley Orgánica de Educación Pública), promulgada el 1 de abril de 1941 por el presidente Manuel Prado. Era un ente aún al interior del Ministerio de Educación Pública. Más tarde, por Decreto Supremo No 48, del 24 de agosto de 1962 (perfeccionado por Decreto Ley 14479, del 17 de junio de 1963), se crea la Comisión de Cultura Nacional, estableciéndose la Casa de la Cultura del Perú (Coloma, 2001a). Ella se disolvió para crearse el INC (Decreto Ley 18799, del 9 de marzo de 1971), como un organismo público descentralizado del sector Educación. 
Cornejo estima que entre 1968 y 1975 la política cultural peruana alcanzó su más alto grado de desarrollo y articulación, esto debido al lugar que ocupa la cultura dentro del proyecto nacional que se diseña y trata de llevarse a la práctica (p. 114), aunque reconoce que la diversidad, el pluralismo y la interculturalidad no eran, propiamente, los valores que orientaban la política cultural.

El ejemplo de «modernización» de la década de 1940 — para Cornejo— revela que parte del estamento gubernamental había tomado conciencia de la importancia para la vida de la nación la dimensión cultural, pero sobre todo que se comprendía que el Ministerio de Educación ya no podía cumplir una tarea que en sentido estricto no le correspondía: impulsar la cultura nacional en sus aspectos extraescolares y para lo cual era necesario existiesen o se creen organismos pertinentes, la Dirección Artística y Extensión Cultural (p. 67).

En términos generales, puede decirse que esta publicación busca poner en evidencia el magro resultado de diferentes esquemas de modernización administrativa y de normatividad, e incita a asumir ideas que dirijan a un paradigma más relevante en el que las variables de racionalidad política, burocrática y los condicionantes externos sean elementos centrales, aunque no únicos, de análisis (Cornejo, 1987, p. 2).

Tras este sucinto repaso a la metodología y contenido de los textos históricos de Ansión y Cornejo, veamos las coincidencias en ambos autores. Tanto Anhelos y sin Sabores (1986) como Estado y cultura en el Perú Republicano (1987) son obras de agudos investigadores que pertenecen a una generación que tras el militarismo de la década de 1970 abrazó el discurso liberal del Estado como forma política representativa, dominante, coherente y compleja que en los siglos XIX y XX atravesó por debilidades, anacronismos o crisis que se proyectaron en las políticas culturales. Como creyentes en tal discurso, los autores suponen que tanto el «progreso» como el «desarrollo» cultural son resultados del buen funcionamiento de los órganos estatales o buenas políticas y por ello se esmeraron en brindar recomendaciones para reformar y corregir las posibles fallas y errores en la política y los órganos culturales en la estructura estatal en tiempos de democracia.

A lo aquí indicado, debe referirse que en ambos tratados históricos las políticas culturales son vistas como una «posibilidad» para que el Estado puede hacer «realidad» el «Perú imaginado» (fraterno y democrático) pero, también, no hay reparos en cuestionar las oportunidades perdidas por la permanente falta de criterio de las muchas normas y medidas culturales porque no satisficieron requerimientos históricos básicos de la sociedad peruana (el reconocimiento y la inclusión). Ansión y Cornejo nos entregaron obras históricas, básicamente, fundadas en la idea que el principal productor de las políticas culturales es el Estado.

Ambos intentaron estudiar sistemática y multidisciplinariamente la política cultural del Estado relacionándola con trasformaciones sociales y políticas. Analizan la forma y patrón, eficiencia e impacto social de la política cultural estatal. En los textos de Ansión y Cornejo es imposible ubicar un cuestionamiento claro a las claves ideológico-teóricas que sustentaron las políticas culturales de la década de 1970; mucho menos afirmaciones que sugieran que el aparato cultural que fundó Velasco fracasó pues se organizó en base a secciones alusivas y abstractas y no de criterios que permitían acciones concretas. Tampoco refieren que la política cultural del régimen de Velasco no fue una política pública en el sentido de que no fue formulada en el espacio público por diferentes actores sociales culturales. 


\section{Siglo XXI: Historia de las políticas culturales como historia del campo cultural}

[...] la política cultural no es sólo política de Estado sino política pública, en cuanto en ella participan diversos sectores de la sociedad, lo que hoy se denomina sociedad civil (Bravo, 1992, p.12).

En estos tiempos de regreso a la sociedad civil y de defensa de la esfera pública, la dimensión cultural de la democracia pasa al primer plano. También por el énfasis (posmoderno) en las diferencias y en la diversidad. Todo forma parte de una búsqueda de participación (quizás ya no se hable de socialismo participativo, pero sí de democracia participativa, y dudo de que las fuerzas de ambas expresiones resulten muy distintas) (Roncagliolo, 1999, p. 15).Si Cornejo Polar concibió una historia crítica de los desplazados de las políticas culturales desde el surgimiento del Estado Republicano en 1821 hasta 1985, nada impidió al arqueólogo, etnólogo, profesor, consultor de la UNESCO y Director General del INC (entre agosto del 2002 y julio de 2006), Luis Guillermo Lumbreras (Ayacucho, 1936), ir más allá y elaborar "El papel del Estado en el campo de la cultura" (2006), un ensayo en donde narra el desempeño estatal en cultura desde la irrupción del Estado en el Perú —en tiempos prehispánicos— hasta el siglo XXI.

Si Cornejo Polar concibió una historia crítica de los desplazados de las políticas culturales desde el surgimiento del Estado Republicano en 1821 hasta 1985, nada impidió al arqueólogo, etnólogo, profesor, consultor de la UNESCO y Director General del INC (entre agosto del 2002 y julio de 2006), Luis Guillermo Lumbreras (Ayacucho, 1936), ir más allá y elaborar "El papel del Estado en el campo de la cultura" (2006), un ensayo en donde narra el desempeño estatal en cultura desde la irrupción del Estado en el Perú — en tiempos prehispánicos — hasta el siglo XXI.

Pero Lumbreras es alguien que intenta explicar las acciones concretas del Estado sobre el «campo cultural» y no especular sobre cosas genéricas, como la «realidad cultural nacional» (Lumbreras, 2006, p. 76). Para el autor, el «campo cultural» es una proyección de la propia existencia humana, un producto histórico colectivo palpable e inteligible. Y a este ámbito Lumbreras circunscribirá todos sus análisis. Así, para el etnólogo, en principio existe el «espacio cultural», el espacio donde se mueven todos (Lumbreras, 2006, p. 82), en el que está comprendido todo el espectro de las condiciones de existencia, que van desde las prácticas productivas hasta las de consumo cotidiano y festivo, pasando por los códigos de salud y vienes y los de las relaciones de la población con el medio (Lumbreras, 2006, p. 83).

Por ejemplo, en la fase de nuestra historia donde hubo «colonización», los componentes del espacio cultural (inclúyase también sus formas simbólicas, modelos de conducta y hábitos de consumo) fueron percibidos - por el colonizador - como diferentes, posteriormente fueron discriminados, reprimidos y finalmente suplantados (Lumbreras, 2006, p. 83). Se impuso sobre dicho espacio la política cultural de un Estado de ocupación hispano colonial. Tal política respondía a los intereses de un régimen externo, el español.

Tras la Independencia (1821) e inicios del siglo XX, un Estado de base criolla se encargó de imponer al ámbito cultural una política que privilegiaba lo externo sobre lo propio, adversa a las poblaciones nativas, promoviendo códigos y modelos de vida alienada (Lumbreras, 2006, p. 79). Esta política también fue «copista», pues se la diseñó apartada de cualquier plan de generación de tecnologías propias o condiciones para el desarrollo nacional. Esa política respondía a los intereses de una minoría social o las conveniencias extranjeras.

$\mathrm{Y}$, desde la segunda mitad del siglo XX, «las condiciones de existencia»y los componentes simbólicos y materiales del espacio cultural comenzaron a ser vistos por el Estado contemporáneo como «temas» que debían manejarse desde especializadas dependencias públicas (Lumbreras, 
2006, p. 83). Al acto de racionalización estatal del espacio cultural el autor denomina «institucionalización de la cultura». Esa institucionalización era una respuesta al imperativo de organizar la acción del Estado y la cultura de conformidad a las necesidades de la época, a los intereses nacionales o las exigencias del conjunto social (insertar al país y cultura al contexto internacional, fomentar la integración cultural, fomentar el respeto a la diversidad, ciertos valores y el desarrollo espiritual).

Para este intelectual, el Estado contemporáneo comenzó la institucionalización de la cultura a inicios de la década de 1940 con la creación de la Dirección Artística y Extensión Cultural del Ministerio de Educación Pública (1941) cuya labor era difundir, entre los estudiantes, todo lo referido al campo de las bellas artes y patrimonio histórico, evidenciando así que el trabajo de dicha dependencia se basó en concepciones de cultura bastante «restrictivas» y pasatistas (Lumbreras, 2006, pp. 82-83).

No hubo intención de incorporar "otros" espacios en la nueva estructura oficial de la cultura, como los que se ventilaban en el Instituto Indigenista, asociado el Ministerio de Trabajo y Asuntos Indígenas, o los de la cuestión agraria o alimentaria y de salud. Nadie asumía que ellos podían pertenecer al gran campo de la cultura (Lumbreras, 2006, p. 96).

Asimismo, considera que en las décadas de 1960 y 1970 al campo cultural instituido continuaba aplicándosele políticas «tradicionalistas» pues, por lineamientos, el INC estuvo incapacitado de incorporar organismos públicos que veían temas de ciencia, tecnología, comunicación masiva, turismo y desarrollo (Lumbreras, 2006, p. 108), vale decir, ámbitos que también pertenecen al campo de la cultura. En consecuencia - para Lumbreras-, ni las políticas culturales instituidas ni sus órganos correspondientes pudieron definir prioridades ni diseñar estrategias que convoquen al cambio en esta época, ni a las particularidades del país.

Puede decirse que Lumbreras, fundamentalmente, estudia y piensa la maquinaria cultural «especializada», piensa su origen, su trayecto histórico y funcionamiento. Por momentos, la encuentra ineficiente o desbordada de gestiones incapaces de orientar y liderar el «sector cultura». Estima que los organismos públicos han venido ventilando temas de ciencia, medio ambiente o interculturalidad, de modo aislado; sin embargo, nunca pierde la esperanza en que el Estado instituya el campo cultural de conformidad a los requerimientos ciudadanos y de la contemporaneidad.

Diferentes pasajes del texto pueden convencernos que Lumbreras no logra el objetivo de reconstruir la memoria del desempeño estatal en el campo cultural a partir de casos concretos y que los microcosmos y cotidianeidades generadas al interior del sector son totalmente descuidadas; sin embargo, este texto tiene el mérito de no caer en el intelectualismo ni la especulación fútil.

El algoritmo conceptual («campo cultural») le permite estudiar casos puntuales, como la configuración de instituciones del sector cultura, o los entrecruzamientos de funciones e injerencia institucional en la forja de políticas culturales, incluso enfocarse en temas subjetivos como la intolerancia cultural o indagar por la ideología del grupo que impuso, desde el Estado, sus políticas sobre este campo. El autor tiene una única unidad de análisis (el campo cultural), no obstante, éste presenta la ventaja de integrar distintos sectores de la cultura a la hora del análisis histórico.

En este estudio histórico de Lumbreras la cultura deja de estar subyugada a los diferentes devaneos gubernamentales o de los grupos políticos dominantes para ser tratado de modo institucional, es decir, autónomo, en todo caso, subyugado a su propio devenir y lógica. Para 
terminar, debe mencionarse que el artículo de Lumbreras es la pieza fundamental de una recopilación dirigida por gestores, críticos y teóricos de la cultura con una especial narrativa y posición frente al Estado y cultura que Lumbreras conoce y, en cierto sentido, compartiría.

El libro donde va incluido este opúsculo de Lumbreras se titula Políticas culturales: Ensayos críticos (2006). Es una compilación a cargo del maestro y gestor cultural, Guillermo Cortés, y del profesor de literatura y especialista en estudios culturales, Víctor Vich. La mayoría de artículos allí reunidos no tienen un estilo homogéneo. Fueron escritos por voces no estatales del Perú que controlan recursos simbólico-culturales y con capacidad de generar sus propias líneas de acción o con capacidad de agencia, como suele decirse hoy.

En general, estos compiladores y ensayistas no se manifiestan desde la institucionalidad o un sector específico de la cultura. Pertenecen a una generación que estuvo cercana a las controversias sobre populismo autoritario — que socavó el estado de derecho y pluralismo a fines del siglo XX - y que acude a ciertos tópicos del liberalismo político — reconocimiento de la diferencia, participación ciudadana y diálogo público - o de los discursos de la subalternidad y ecologismo para ofrecernos sus interpretaciones de lo que estaría en juego en las políticas implementadas en años recientes por el poder central sobre el campo cultural.

Críticos del Estado fujimorista, la dictadura eimpunidad y esperanzados en la democratización cultural, abogan por la identificación y desmontaje de las identidades creadas por mandato oficial, que manipula o elimina la capacidad política de las personas, es decir de reconocerse como ciudadanos y actuar en el espacio público en la elaboración de políticas culturales (Vich, 2006, pp. 61-63); demandan al Estado narrativas inclusivas o promover diálogos interculturales globales. A eso se suma su ímpetu por deconstruir el nacionalismo en sus dimensiones antagónicas y contradictorias o los discursos que asumen los Estados y que los lleva a censurar cualquier gesto de crítica que le sale al frente o a dificultar todas las iniciativas empresariales y privadas en cultura.

Su crítica cultural delata, incluso, un deseo de friccionar los paradigmas base de las políticas culturales tradicionales, como «desarrollo cultural», «patrimonio», «cultura nacional»; un deseo de innovar la lectura de las actuales políticas culturales. En la Introducción a Políticas culturales: Ensayos críticos exponen su idea de que el Estado no es el único actor con capacidad de generar normas y gestionar la cultura, mucho menos de tener la exclusividad de las iniciativas culturales (Cortés y Vich, 2006, p. 12). Y si Jorge Cornejo abordó el tema de la exclusión cultural desde un punto de vista ético, en este libro, partiendo de la premisa que vivimos en sociedades interdependientes, los autores convocados discuten éticamente qué tipo de comunidades se pueden crear y sostener basándose en nuestra «diversidad».

En general, la mayoría de las opiniones de gestores, críticos y teóricos reunidos en esta obra destacan porque se concentran en aspectos que amplían enormemente los horizontes de la investigación y la reflexión histórica sobre políticas culturales, y para suplir este vacío Vich y Cortés tuvieron a bien convocar al Dr. Luis Guillermo Lumbreras y publicar su ensayo histórico.

\section{La historia en las diferentes propuestas de acción cultural para el Estado}

[...] el terreno de la actividad cultural [...] en la actual coyuntura corre el riesgo de quedar exclusivamente en manos de expertos tecnócratas, encargados hoy del "desarrollo" ya no solo económico sino social y cultural (Yúdice, 2002, p. 116). 
"Bases para la política cultural de la Revolución Peruana" (1977) es el primer documento que contiene explícitamente las propuestas de acción cultural que debía seguir el Estado. En aquel documento, elaborado por el principal órgano consultivo del INC: el Concejo General de Cultura (CGC), la «cultura peruana» era una idea posible de concretar y los paradigmas del socialismo humanista -inspirado en movimientos revolucionarios humanistas y algunos proyectos intelectuales sin cara institucional, como la filosofía de la liberación, teoría de la Dependencia y del colonialismo- los elementos inspiradores (CGC, 1977, p. 15).

Como todo programa, contiene un diagnóstico, en este caso un diagnóstico histórico de la «realidad cultural» de la nación. Es bastante sucinto e ideologizado, pero puede considerarse el principal antecedente de las historias de políticas culturales en el Perú, pues hay un intento de diferenciar las políticas culturales del pasado (conservadoras) de la actual («revolucionaria») (CGC, 1977, p. 15). Incluso, hay el deseo de caracterizar y enjuiciar ambas políticas vinculándolas a procesos históricos sociales o temas estructurales.

Esta narrativa oficial cuestiona todo el valor social de las políticas culturales durante los siglos XVI-XX o levanta una barrera que impide la historicidad de las políticas culturales al desmerecer, ideológicamente, las políticas culturales no revolucionarias. Para los autores de esta propuesta, la política cultural estatal del presidente Juan Velasco Alvarado no tiene antecedentes. Es fundacional, es revolucionaria, nacional y participativa. Incluso no toma en cuenta la estructura cultural estatal preexistente. Se concentra en describir y exaltar el sistema cultural que se ha creado.

En 1983, el Concejo Nacional de Cultura del INC (CNC), presentó el segundo planteamiento de acciones generales en cultura de nuestra historia que denominó "Documento de bases para la formulación de la política cultural". Tal propuesta estuvo motivada por la ideología del humanismo democrático (CNC, 1983, p. 13) y "perspectivas universales de cultura», hecho que significaba el cierre de un ciclo de propuestas de política cultural explícitas basadas en el paradigma nacional populista o del humanismo revolucionario. Se pensó que con eso podría evitarse el direccionamiento o imposición de valores desde arriba o podría abrirse el Estado a las «consideraciones de la pluralidad cultural» (CNC, 1983, p. 12).

Pero, en contra de lo esperado, el diagnóstico de las políticas culturales en este documento democratizador contiene rastros de una interpretación histórica que otorga amplio poder explicativo a arquetipos del nacionalismo (como «mestizaje cultural»), a la idea de «fractura» cultural debido a la influencia e invasión foránea (CNC, 1983, p. 11), a la división arte culto (occidental) - arte primitivo (local), etcétera. Es más, incluye un gesto desconcertante pues, a diferencia de su antecesor, este plan no se dirige a todos los que puedan participar de la cultura (las mayorías), todo lo contrario, solo se somete a la opinión de quienes están ligados a la actividad creativa, a los subsectores del campo cultural (como de la industria cultural), a los consejos técnico profesionales del sector cultura, y finalmente a los «interesados» (pp. 4, 45). Fue un plan para instituciones urbanas y el sector cultural privado o estatal.

Para Juan Ansión la ambigüedad en este documento se debe a que fue redactado, en sus distintas partes, por personas diferentes, razón por la cual, refleja discrepancias:

Tal ambigüedad permite entender la política de Acción Popular [1980-1985]. La consecuencia sería una pérdida de autoridad por parte del Estado, por su propia indefinición y una suerte de "dejar hacer" a nuevos actores culturales que tampoco significa una política liberal consecuente, sino más bien un dejar que se enfrenten libremente varias alternativas políticas, sin permitir que ninguna prevalezca, cayéndose en la indefinición del Estado y en la mediocridad, que de 
algún modo significa para el gobernante una garantía de poder, aunque a la larga esto lo vaya desgastando irremediablemente (Ansión, 1988, p. 109).

El siglo XXI presenta una situación interesante. Se dan varias propuestas de acción cultural para el Estado. A saber: "Lineamientos para una política cultural del Perú. Documento de trabajo 2001-2006" (presentado por la Comisión Nacional de Cultura, 2001); "Lineamientos y programas de política cultural del Perú 2003-2006" (presentado desde el INC, 2002); “Orientaciones estratégicas para el impulso de las políticas culturales en el Perú" (auspiciada por el INC y el apoyo de la Agencia Española de Cooperación internacional, de especialistas y de sociedad civil, 2008); "Lineamientos de política cultural 2013-2016" (diseña, ejecuta y supervisa: Ministerio de Cultura del Perú, en conjunción con los sectores del mercado y sociedad civil, 2013); "Elaboración de políticas nacionales de cultura 2018-2021" (diseña, ejecuta y supervisa: Ministerio de Cultura, en conjunción con los sectores del mercado y sociedad civil 2017) (Ministerio de Cultura, 2017, pp. 37-47).

En tales documentos el Perú como lugar donde existe una ciudadanía basada en nuestra diversidad o como lugar donde está garantizado el derecho a la cultura sin barreras ni distinciones son ideas que pueden cobrar realidad y las propuestas del liberalismo político reconocimiento de la diferencia, participación ciudadana y diálogo público- el elemento guía.

Prima, en estas propuestas, el deseo de reconocer la historicidad de las políticas culturales del Perú, situarlas en el texto internacional. Es más, tales propuestas son diseñadas en perspectiva histórica. Numerosas páginas se destinan a mostrar los hitos centrales en el desarrollo de las políticas nacionales y mundiales, como la creación de la Dirección de la Dirección Artística y Extensión Cultural del Ministerio de Educación Pública (1941), o del INC en 1972, pasando por la presentación cronológica de los diferentes lineamientos internacionales sobre políticas culturales. También, se dan alcances de los diferentes planes y lineamientos de acción cultural que se realizaron en las últimas décadas. Incluso, se explican conceptos de uso cotidiano en el sector.

Pero en las propuestas de la referencia se abandonó el diagnóstico de la historia de las políticas culturales basado en paradigmas nacionalistas o asociado a procesos sociales o temas estructurales. Son historias que compendian acontecimientos del sector. En ellas se habla de cultura como un fenómeno ligado a las artes, el saber, y la educación y (en la última propuesta, del 2017) hay un bajo reconocimiento de su papel social e incidencia socio-económica. Estas fueron elaboradas por gestores culturales, técnicos y servidores públicos que conocen a la perfección el funcionamiento y racionalidad del campo cultural en tiempos de «debilitamiento» del Estado, del papel de las ideas y ciudadanía en él.

Las propuestas del siglo XXI delatan una idea predominante: el caos del sector cultura no será ordenado por la ideología, la utopía o por mandato; se ordenará con método y recetas técnicas, con la aplicación de conocimientos brindados por las disciplinas surgidas en el propio sector cultura: museología, patrimonio, gestión cultural, turismo, industria cultural, archivística, bibliotecología, etcétera. En ese sentido, la historia del sector cultura, en estas propuestas, es la historia de su especialización y conquista de su eficiencia - nunca lograda—, vía el método y aplicación de conocimientos muy especializados.

\section{Conclusiones}

Las obras de historia de las políticas culturales en el Perú evidencian una evolución metodológica. Surgen en la década de 1970 como producto de la especulación (nacionalista) y no de la indagación metodológica ni manejo teórico especializado. Establece una cronología básica: 
política cultural del pasado (colonialista) y la actual («revolucionaria»). Su objetivo es someter a juicio ético las formas de intervención de los Estados (prehispánico, colonial, republicano, y revolucionario) a fin de orientar la cultura «autentica» y «nacional». Hay una concentración en temas estructurales como la dependencia, colonización y dominación. Los elementos básicos de análisis son la «ideología» del colonizador, la extirpación, la enajenación y «desintegración» de la cultura nacional.

Enfocado en abstractos, como la «realidad» de la «nación peruana», este análisis dejó de lado las propias acciones gubernamentales concretas (los mecanismos de toma de decisiones, la heterogeneidad de los actores involucrados, los intereses y las ideologías que impregnan sus posturas). En este periodo, se carecía de estudios sobre gestión y administración pública y cultural, el accionar concreto del Estado no concitaba el interés de las ciencias sociales ni políticas. Tales historias obvian elementos empíricos o datos fácticos que permiten reconstruir con detalle los universos del área cultural. Son visiones históricas portadoras de propuestas y posturas políticas (nacionalistas) antes que un reflejo del análisis histórico.

En la década de 1980, la historia de políticas culturales es producto del trabajo sistemático y multidisciplinario. Busca explicar el papel del Estado en la cultura en relación a cambios sociales y políticos definidos (Ansión), así como el por qué hay desencuentro entre las políticas culturales del Estado y la realidad socio cultural del país (Cornejo). Para conformar la explicación, se analiza la instalación de la política cultural en el aparato estatal, dispositivos legales, la subjetividad de los servidores estatales (Ansión), diferentes mecanismos de elaboración de políticas (Ansión). También se establece cronologías de las políticas culturales según los tipos de gobierno. Estas historias evidencian el deseo que cultura y Estado concreten la Republica imaginada, no utopías revolucionarias de base nacionalistas.

A inicios del siglo XXI, las historias sobre políticas culturales se concentran en procesos o acontecimientos puntuales y específicos: los ocurridos en el «campo cultural» (es el caso de la obra del Dr. Luis Lumbreras). La política cultural es explicada por los procesos y lo acontecido en el campo cultural. Presentan la política cultural como una forma de acción que solo puede entenderse en el marco de prácticas instituidas al interior del campo cultural. Por último, destierran todo intento de estudiar la historia de las políticas culturales a partir de su influjo en campos menores o autónomos, como el intelectual, literario o científico.

En los diferentes planes y lineamientos de acción cultural del siglo XXI se dejó de lado la narración ética, utópica y politizada de las políticas culturales en el Perú. La acción estatal en cultura no es presentada en relaciona a procesos histórico sociales o temas estructurales. Se busca establecer una línea histórica progresiva del propio sector cultura. Incluso, ubicarla en un contexto global. Se citan hechos y productos concretos, como la institucionalización del espacio cultural, o se hace una presentación cronológica de los diferentes planes de acción cultural para el Estado. Inclusive se explican conceptos de uso cotidiano en el sector. Son historias compendio a fuerza de ser didácticas imparciales y centradas en sí mismas (el sector cultural Estatal).

En la década de 1970, los primeros diagnósticos de las políticas culturales fueron concebidas por intelectuales al servicio de un régimen revolucionario centralista de gran capacidad coercitiva; luego — en la década de 1980 - por analistas y estudiosos de la acción estatal en materia de cultural. Mientras que en el siglo XXI son realizadas por académicos, servidores públicos, gestores y técnicos que conocen a la perfección el funcionamiento y racionalidad del campo cultural en tiempos de «debilitamiento» del Estado, del papel de las ideas y ciudadanía en él. Son liberales y apolíticos. 
Las historias de política cultural efectuadas entre 1970 y 1980 se fundamentaron en consideraciones provenientes de estudios de historia social, de la antropología cultural (de A. L. Kroeber), incluso por las «explicaciones» anticolonialistas y humanistas de la «realidad»; las efectuadas en los 2000 se fundan en los conocimientos brindados por las disciplinas surgidas en el propio sector cultura: museología, patrimonio, gestión cultural, turismo, industria cultural, archivística, bibliotecología, etcétera. El trabajo de Lumbreras se basó en ambos aportes, pero sobre todo en la libre interpretación de los mismos.

A diferencia de Cornejo, que en su análisis cuestiona — principalmente — la indiferencia y discriminación del Estado a las culturas otras, Lumbreras intenta analizar la cultura principalmente desde la óptica de la defensa de las identidades o respeto de la diferencia cultural.

El presente recuento y estudio de trabajos de historia de las políticas culturales en el Perú sin duda es incompleto porque, por ejemplo, se prescindió de obras que tratan el tema desde la perspectiva de la diplomacia cultural (Azurín, 1991). Las investigaciones de diplomacia cultural buscan dar a conocer cómo fue la política cultural exterior peruana, en nuestro caso, debimos limitamos al estudio de obras que pretenden narrar cómo fue la política de cultura orientada al ámbito nacional.

Pero una cosa es evidente: escasean obras de historia de políticas públicas de cultura en el Perú. Apenas, se han publicado exiguos estudios sobre Estado a partir de su papel en la cultura o de las políticas culturales vinculadas a cambios sociales y políticos. Sigue pendiente el estudio del fenómeno cultural desde el punto de vista de los creadores, transmisores y receptores de la cultura. No se ha investigado históricamente a los diferentes actores gubernamentales, sociales y privados que - mediante su influencia personal, la presión social, el debate público y el consenso - buscaron intervenir o influenciar en la creación o implementación de políticas públicas de cultural. Ha primado el análisis centrado en políticas gubernamentales y no se ha incurrido en el enfoque de actores sociales.

A esto se suma el hecho de que falta ampliar el horizonte temático, geográfico, así como reflexivo, de las políticas culturales. La influencia de la cotidianeidad en el diseño y concreción de políticas culturales no ha sido tratada históricamente. No se ha examinado - históricamentelas formas y estilos de negociación entre la industria cultural y el sector cultura estatal. Asimismo, no hay obras sobre la «cultura» en el desarrollo administrativo del Estado moderno, lo que equivale a decir que no existen análisis históricos de la trayectoria de la idea de «cultura» en el Estado peruano. Esta ausencia podría ser la consecuencia natural de una falta de definiciones teóricas sobre historia administrativa. Mientras tanto, está pendiente dar respuesta a la pregunta ¿por qué la cultura debía legitimar el desarrollo administrativo del Estado peruano? o ¿a partir de cuándo la cultura es importante para definir la línea política del Estado?

Carecemos de obras históricas sobre los lineamientos internacionales en cultura y su influencia en la configuración de los organismos estatales de cultural. También, existe otra ausencia clave: no hay estudios de legislación cultural en el Perú, apenas pueden ubicarse en la internet compilaciones de Leyes de creación de diferentes órganos de cultural (Coloma, 2001b). Salvo el caso del patrimonio, no existen estudios que nos digan si el Estado pudo implementar, o no, las numerosas propuestas de acción cultural. Los estudios se han concentrado en narrar, cronológicamente, el desempeño estatal a fin de orientar la cultura. En ellas priman los actores impersonales, la entelequia Estado; habría que apostar por etnografíar - históricamentediferentes casos, actores, acciones e iniciativas político culturales, quizá ello pueda contribuir a 
incluir en la agenda pública nuevos temas y derroteros pero sobre todo a «pensar» las políticas culturales que se aplican en la actualidad.

\section{Referencias}

Alcalde, J. (1998). La idea de desarrollo del tercer mundo. La visión inglesa y norteamericana: 1900-1950. Lima: Centro de Investigación de la Universidad del Pacífico.

Alcalde, J. (agosto de 1999). Desarrollo, subdesarrollo y decadencia social. Socialismo y Participación, 85, 9-25.

Ansión, J. (1988). Anhelos y sinsabores. Dos décadas de políticas culturales del Estado Peruano. Lima: Grupo de Estudios para el Desarrollo.

Arróspide, C. (1975). Cultura y liberación. Lima: Instituto Nacional de Cultura.

Azurín, C. (1991). Bases para una política cultural exterior peruana. Lima: Academia Diplomática del Perú.

Bravo, M. E. (1992). Políticas culturales y desarrollo cultural en Colombia. Medellín: Consejería Presidencial para Medellín y el Área Metropolitana.

Bueno, L. (7 de junio de 1974). Socialismo y Participación. Los intelectuales responden. Oiga, 13(578), 14-17.

Bueno, R. (enero-marzo 2005). Jorge Cornejo Polar (Arequipa, 1930 - Lima, 2004). Revista Iberoamericana, LXXI(210), 305-306.

Bustamante. C. (7 de diciembre de 1975). Hacia una participación cultural. Suceso. Suplemento de Correo, p. 4-5.

Coloma, C. (2001b). El Instituto Nacional de Cultura. Organización y funciones 1971-2001. Serie Documento de Trabajo. Lima: Instituto Nacional de Cultura, Centro Nacional de Información Cultural.

Coloma, C. (2001a). La Comisión Nacional de Cultura y la Casa de la Cultura. 1962-1971. Serie Documento de Trabajo. Lima: Instituto Nacional de Cultura, Centro Nacional de Información Cultural.

Concejo General de Cultura del INC (1977). Política Cultural del Perú. París: UNESCO.

Consejo Nacional de Cultura (1983). Documento de bases para la formulación de la política cultural. Lima: Banco Central de Reserva del Perú.

Cornejo, J. (1979). Reflexión en torno al desarrollo cultural. Cielo Abierto, 1(2), 24-31.

Cornejo, J. (1987). Estado y cultura en el Perú republicano. Serie: Cuadernos de Historia III. Lima: Universidad de Lima, Departamento Académico de Ciencias Humanas.

Cornejo. J. (ed.) (1989). Las políticas culturales en América Latina: Una reflexión plural. Lima: Asociación Peruana de Promotores y Animadores Culturales.

Cortés, G. y Vich, V. (ed.) (2006). Políticas culturales: ensayos críticos. Lima: Instituto de Estudios Peruanos.

Cortés, G. (2006). “Tan cerca y tan lejos: los vaivenes de las políticas culturales”. En Vich, V. y Cortés, G. (ed.). Políticas culturales: Ensayos críticos (pp. 19-43). Lima: Instituto de Estudios Peruanos.

Escobar, A. (octubre de 1977). Notas sobre política cultural. Socialismo y Participación, 1(1), 89-92.

García, N. (1987). "Políticas culturales y crisis de desarrollo: Un balance latinoamericano". En García, N. (ed.). Politicas culturales en América Latina (pp. 13-61). México D. F.: Editorial Grijalbo, S. A.

García, N. (2005). "Definiciones en transición”. En Daniel M. (comp.). Estudios latinoamericanos sobre cultura y transformaciones sociales en tiempos de globalización (pp. 57-67). Buenos Aires: CLACSO.

Herrera, F. (1977). América Latina y sus políticas culturales. París: UNESCO.

Hildebrandt, M. (4 de mayo de 1976). La política cultural del Perú tenía que ser una política de cambio. La Prensa, p. 21.

Lumbreras, L. (2006). "El papel del Estado en el campo de la cultura". En Cortés, G. y Vich, V. (ed.). Políticas culturales: Ensayos críticos (pp. 71-111). Lima: Instituto de Estudios Peruanos.

Mejía, J. L. (setiembre - diciembre de 2004). ¿Derechos sin Estado? Tres momentos de la institucionalidad cultural en América Latina. Pensar Iberoamérica. Revista de Cultura, (7). Recuperado en 12 de julio de 2017 de http:// www.oei.es/historico/pensariberoamerica/ric07a05.htm 
Ministerio de Cultura (2012). Lineamientos de política cultural 2013 - 2016. Lima: Ministerio de Cultura.

Ministerio de Cultura (2017). Política nacional de cultura. Tú también creas la Política Nacional de Cultura. Marco conceptual para la elaboración de politicas culturales en el Perú. Lima: Ministerio de Cultura.

Ortega, J. (5 de octubre de 1975). Cultura y Revolución. Suceso. Suplemento de Correo, p. 18-19.

Ossio, J. (1986). Patrimonio cultural del Perú. Balance y perspectivas. Lima: Fomciencias.

Roncagliolo, R (abril de 1999). Nota para una conversación sobre políticas culturales. Socialismo y Participación, 22(84), 9-17.

Santuc, V. (noviembre de 1993). La experiencia del Velasquismo. Socialismo y Participación, 63, 83-100.

Una dirección reorganizada y la cultura. (22 de diciembre de 1955). La Prensa, p. 10.

Yúdice, G. (2002). El recurso de la cultura. Usos de la cultura en la era global. Barcelona: Editorial Gedisa, S. A. 